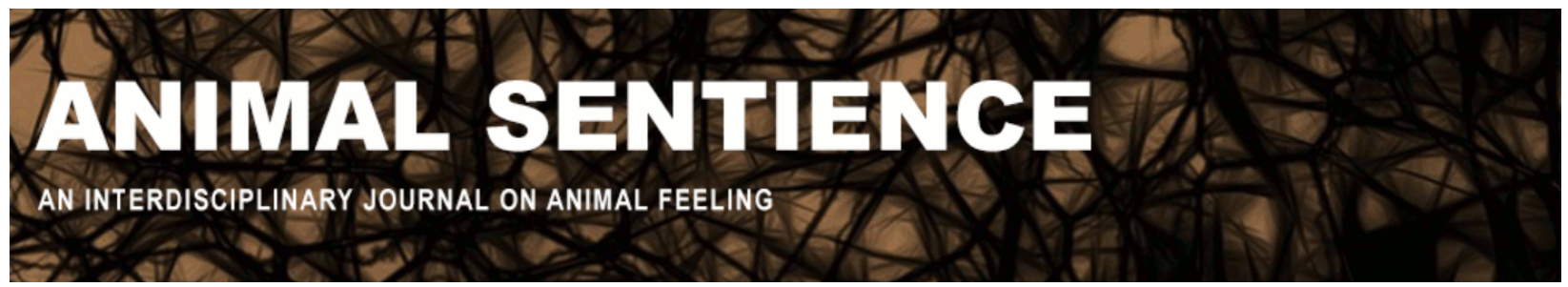

Juergens, Uta Maria (2018) Human and nonhuman animals: Equals in uniqueness. Animal Sentience 23(2)

DOI: $10.51291 / 2377-7478.1378$

Date of submission: 2019-01-22

Date of acceptance: 2019-01-24

(c) (†)

This article has appeared in the journal Animal

Sentience, a peer-reviewed journal on animal

cognition and feeling. It has been made open access,

free for all, by WellBeing International and deposited

in the WBI Studies Repository. For more information,

please contact

wbisr-info@wellbeingintl.org.

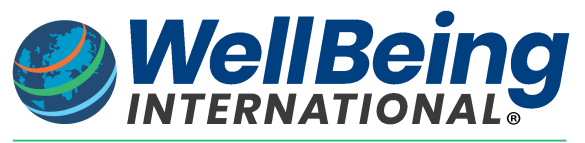

SOLUTIONS FOR PEOPLE, ANIMALS AND ENVIRONMENT 


\title{
Human and nonhuman animals: Equals in uniqueness
}

Commentary on Chapman \& Huffman on Human Difference

\author{
Uta Maria Juergens \\ Department of Environmental System Science \\ Swiss Federal Institute of Technology Zürich
}

\begin{abstract}
Chapman \& Huffman attack the idea that humans are unique and therefore superior to nonhuman beings. They call on humankind to use their "intellect to change [their] actions." I am in full accord with their line of thought, which differentiates uniqueness from superiority and enjoins humans to take responsible action. I suggest, however, that humans are unique with regard to cognitive fluidity. The same conclusions can be reached via another argument based on human uniqueness.
\end{abstract}

\footnotetext{
Uta Maria Juergens investigates humanwildlife relations in a project funded by Deutsche Wildtier Stiftung. Her further interests range from synaesthesia research to anthrozoology and the philosophy of mind. She is a writer and investigates human-nature relations from an artistic angle. Website
}

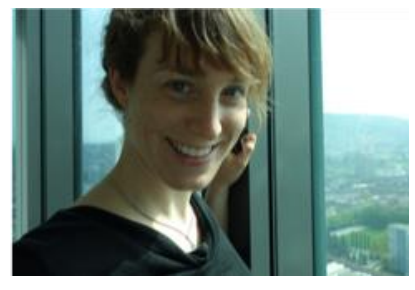

\section{Introduction}

In their target article, Chapman and Huffman (2018) (C \& H) take issue with the proposition that humans are unique in their capacities and hence rank highest in the chain of being. They hold that the human-animal distinction ought to be revisited, arguing that many infamous criteria for upholding that distinction (e.g., use of tools and medicine, skill and complexity of architecture, putative cognitive superiority) have been refuted by empirical evidence. They conclude by appealing to humankind to use their capabilities for the benefit of all beings.

I see a slight contradiction in this line of thought: $\mathrm{C} \& \mathrm{H}$ seem to base their passionate call to action on a particular human responsibility to care for the nonhuman world. This responsibility is linked to our "intellect," which is tacitly assumed to be unique to us, as humans.

\section{Humans are unique}

Given the inter- and intra-cultural diversity of humans and the inter- and intra-specific variability of animal forms of life, the question of whether "humans" are unique compared to "animals" does not really make sense. Lobsters possess the most sensitive sense of smell (Derby \& Atema, 1982), termites may be the greatest architects, and humans may be the most skilled users of communication (Dor, 2015) in the animal kingdom. Lobsters, termites, and humans outperform the many other species using chemotaxis, building, and language, respectively, and hence they are unique with regard to these respective capabilities. What differentiates humans from all 
other forms of life, however, is that, as a species, we do all of that: We craft devices that allow chemists among us to "smell" better than lobsters; we develop principles of architecture that enable the Gaudís among us to build more purposeful and stable buildings than termites; and notwithstanding the prowess of bees, dolphins, and great apes in the use of symbols - we are the only species commanding language to this degree of creativity and effectiveness. We exhibit a stunning variety of further outstanding properties - including imposing by far the largest ecological footprint of all species on earth.

The variety and peculiarity of humans' skills represent an essential difference between human and nonhuman animals. I follow Mithen (1996), Tattersall (1998), Shettleworth (2012), and many other scholars in supposing that this essential difference lies in a trait called "cognitive fluidity," i.e., the ability to flexibly and creatively handle mental contents in different domains. This mental flexibility is probably the reason $\mathrm{C} \& \mathrm{H}$ call on us, rather than lobsters or termites, to "change our actions" based on our "intellect": Our unique responsibility flows precisely from our potential for flexible thought and action. If we are cognitively fluid, we can deliberately abandon destructive modes and adopt the more considerate ways of being in the world of which $\mathrm{C} \& \mathrm{H}$ remind us. The fact that we have not yet done so, despite grave evidence that we need to, shows that uniqueness does not equal superiority. When measured by the criterion of ecological sustainability, humans rank lowest despite their unique intellect.

\section{Humans and nonhuman animals are equal}

Human uniqueness does not contradict the equality of all beings on a deeper level. Human and nonhuman animals are alike in two respective, unique ways: individuality and epistemic equality.

Individuality is pervasive in the animal kingdom (and arguably in the plant world, too, see Hall, 2011): Each member of every species is an individual with a unique "personality" and unique capacities (Lestel, 2011; Ogden, 2012). Within each species, outstanding individuals such as some unknown lobster dwelling near Helgoland, a particular tribe of termites in Queensland, or Goethe and Adorno - may excel at their respective "art" even compared to their conspecifics. Some may even be the carriers of an outstanding mutation leading biological or cultural evolution onward. We are the same in being different.

All beings are also epistemic equals (Jürgens, 2017): We tend to take for granted that all beings experience reality in basically similar ways. They don't. Based on von Uexküll's (1909, 1982) concept of animals' Umwelten, we need to acknowledge that each species has its own particular way of creating its experiential world. Moreover, every individual lobster, termite, or human has his or her own unique take on reality. We relate to reality in species-specific ways i.e., in lobster, termite, and human ways - as well as in individual ways. A comparison of lifeforms is in this sense futile. We are "equal" in a deep ontological sense, because our unique subjective spaces defy comparison.

\section{Humans' unique responsibility}

Nonhuman animals' ways of thinking about their respective realities (Jürgens, 2017) and their ways of being in the world may be less flexible than ours. Given the unique human endowment 
of cognitive fluidity and without any ranking of valence implied, C \& $\mathrm{H}^{\prime}$ s appeal to our supposedly unique human responsibility becomes even stronger. Our unique cognitive fluidity has enabled us to exploit the rest of nature in unparalleled ways. It is also the key to understanding the experiential worlds of other beings and to being their caretakers (cf. Berry, 1988, 1999; Cajete, 1994). If we pride ourselves on our unique intellect, we ought to also pride ourselves on assuming the responsibility that comes with it.

\section{References}

Berry, T. (1988) The New Story. In: The Dream of the Earth. San Francisco: Sierra Club Books.

Berry, T. (1999) The Great Work: Our Way into the Future. New York: Bell Tower.

Cajete, G. (1994) Singing Waters: The Environmental Foundation of Indigenous Education. In: Look to the Mountain: An Ecology of Indigenous Education (pp. 74-114). Asheville: Kiwaki.

Chapman, C. A., \& Huffman, M. A. (2018) Why Do We Want to Think Humans Are Different? Animal Sentience 23(1).

Derby, C. D., \& Atema, J. (1982) The Function of Chemo- and Mechanoreceptors in Lobster (Homarus americanus) Feeding Behaviour. Journal of Experimental Biology, 98(1), 317-327.

Dor, D. (2015) The Instruction of Imagination: Language As a Social Communication Technology. Oxford.

Hall, M. (2011) Plants As Persons: A Philosophical Botany. Albany: State University of New York Press.

Jürgens, U. M. (2017) How Human-Animal Relations Are Realized: From Respective Realities to Merging Minds. Ethics and the Environment, 22(2), 25-57.

Lestel, D. (2011) What Capabilities for the Animal? Biosemiotics, 4(1), 83-102.

Mithen, S. J. (1996) The Prehistory of the Mind: A Search for the Origins of Art, Religion and

Science. London: Phoenix.

Ogden, L. E. (2012) Do Animals Have Personality? BioScience, 62(6), 533-537.

Shettleworth, S. J. (2012) Modularity, Comparative Cognition and Human Uniqueness.

Philosophical Transactions of the Royal Society of London B: Biological Sciences, 367(1603), 2794-2802.

Tattersall, I. (1998) Becoming Human: Evolution and Human Uniqueness. Hartcourt.

Von Uexküll, J. (1909) Umwelt und Innenwelt der Tiere. Berlin: Springer/Ulan Press.

Von Uexküll, J. (1982) The Theory of Meaning. Semiotica, 42(1), 25-79. 